International Journal of Biology, Pharmaey and Allied Sciences (IJBPAS)

'A Bridge Betuen caboratory and QRender'

WWW.ijbpas.com

\title{
REPORTING OF ENVIRONMENTAL NEWS IN PAKISTANI AND BRITISH PRESS EXPLORATION OF BALANCE OR BIAS REPORTING
}

\author{
DAR A AND ALI S* \\ Department of Communication Studies, Bahauddin Zakariya University, Multan-Pakistan \\ *Corresponding Author E Mail: shahzadmasscomm@bzu.edu.pk
}

Received 20 ${ }^{\text {th }}$ Oct. 2019; Revised $15^{\text {th }}$ Nov. 2019; Accepted $25^{\text {th }}$ Dec. 2019; Available online $1^{\text {st }}$ April 2020

$\underline{\text { https://doi.org/10.31032/IJBPAS/2020/9.4.5058 }}$

\begin{abstract}
This research article compares the reporting of environmental news in Pakistani and British elite newspapers to explore the balance or bias approach. In the contemporary society environment has become an essential debate within global spectrum. We examine total one hundred five (105) environmental news stories related to Paris climate change agreement in the year 2015-2016. This content analysis finds significant differences in the prominence of frame selection in two Pakistani newspapers (The Dawn and The Nation) and two from United Kingdom (The Telegraph and The Guardian). British elite newspapers present diversity of environmental stakeholders whereas Pakistani leading newspapers are narrower in source range. Interestingly, with slight difference Pakistani and British print media covered Paris climate change with balance approach by dominantly presenting the pro environmental sources but difference in frame and source selection depends on the organizational agenda of each organization.
\end{abstract}

Keywords: Paris climate change agreement, Environment, Balance or Bias reporting. INTRODUCTION

The effort to obtain and maintain balance and objectivity into a news story is a longlasting convention of journalism [1]. However, Gamson and Modigliani [2] indicated, that within a news story interpretation is generally presented through the use of direct or indirect quotations. While balance attained through highlighting the competing views of spokes persons in the news narrative. The journalistic norm of balanced and fair reporting appears to embrace explicit truth 
in the reporting of science and climate change. It has been a collective practical approach of the journalists to disseminate balanced coverage about climate change, instead of a general scientific consensus on the existence of severe climate change conditions [3-5]. In the coverage of climate change the conflicting perspectives are generally problematic, importantly when scientific community harmonise or certain about the real matter [6]. Special interest groups also known as "climate contrarians" are accountable for bringing competing debate in climate change coverage [7]. Climate opponents are well-known for expressing oblivious claims [8] to become in the lime light of media to support their rhetoric argument [7]. Similarly, Foust et al., [9] argued that climate opponents support their ideological interest by opposing claims of scientists about the nature. They explored that apocalyptic framing of climate change challenged the findings that climate change conditions are not anthropogenic instead it's just a natural fate by blamingthescientific community as scaremongers.

However, Holstein and Stocking [8] argued about environmental concern that often opposing claims about environmental issues dependent on journalist's perception whereas, several journalists stated that the role of journalists highly dependent on different factors such as, their understanding about science and their audience perception about it. Often, journalists assumed it as their ethical responsibility to assess the validity of scientific studies by adding personal interpretation, although in some cases journalists avoid to highlight their own opinion and just present the two sided facts of the story. Currently, Boykoff [10] revealed that news stories based on climate change depicting the anthropogenic contribution of climate change increased by over 30\% between 2003 and 2006. While, in 2006 only $37 \%$ news stories related to climate change accounted the journalistic norm of balance, but only $3 \%$ reported in 2003. The emergence of Paris climate change occurred in 2015-16 motivated the aim of this study as an environmental problem. Although there have been plenty of work done on the mass media and environment, a number of studies have emphasized on the reporting pattern of environmental issues in developed countries particularly in United States. Media of developing countries regarding environmental issues have infrequently been examined. An attempt to provide the balanced reporting often leads towards the biased approach due to diverse claims of special interest groups in order to validate the news coverage or provide the view 
point of two sides such as the perspectives of environmentalists and sceptics [3].

The agenda of the study is to compare the role of print media in developing and developed nations to analyse the framing pattern of news stories on Paris climate change agreement and evaluate the journalistic practice of balance reporting while covering this issue. Four newspapers were selected each of two from developed and developing nation, The Dawn and The Nation from Pakistan whereas, The Telegraph and The Guardian from UK. News stories have been selected for this comparative analysis because news reporting is the best way to judge the reporting pattern of journalists.

Findings of this study will provide significant assistance to communicators as well as environmentalists respectively to evaluate the role of print media in developed and developing nations in informing the masses about environmental issues with more accurate and balance reporting. The significance truly based upon the theoretical ground of framing and journalistic norm of balance, which assume that framing of environmental issues in particular frames increase the public understanding of the issue within the context and balance reporting represent the both sides of an issue by giving less opportunity to climate sceptics and dominating approach to environmentalists with an agenda to highlight pro environmental narrative in the media to persuade the audience accurately.

\section{Theoretical Framework}

Specifically, theoretical framework of this study is based on framing by $[\mathbf{1 1}, \mathbf{1 2}]$ and balance reporting approach outlined by Boykoff \& Boykoff, [4] applied to compare the reporting of environmental news in Pakistani and British print media.

The frame is defined "as the lens through which the story was told" [13]. According to Entman [12], to frame is to "select some aspects of a perceived reality and make them more salient in a communicating text, in such a way as to promote a particular problem definition, causal interpretation, moral evaluation, and/or treatment recommendation for the item described". Balance reporting lies in second-order journalistic norm that indicates if a news story dominating with the view point of environmental sources than environmental sceptics, it was taken as balanced story. Journalistic norm of balance reporting in science discourse of environment is different from other social or political issues covered with conventional idea of balance reporting by presenting the both sides with an equal proportion [4]. 


\section{LITERATURE REVIEW}

The aim of this study is subtle and twofold. Firstly, it identifies the audience dependency on media content for information seeking and the role of media in the subject to construct the reality by frames [12] as well as journalistic norm of balance reporting [4]. In the contemporary society masses obtain much of information from media about every field of life. They have very less or no direct access to the information $[14,15]$. In the view of Boykoff \& Nelkin's concluded that people are highly dependent on media for the knowledge and understanding about scientific substances generally and specifically to environmental issues. Majority of the previous studies including [16-19] have generally focused on framing of news in the media and specifically to the news framing of environmental issues with reference to different regions and cultures. An essential comprehension of the present study focused on the transnational comparative analysis of news framing of environmental issues as well as balance reporting of the mainstream print media of Pakistan and United Kingdom on Paris climate change agreement.

Meanwhile, Marukatat, [20] comparatively analyse the environmental news coverage of Kenya and US as developed and developing countries in agenda setting capacity and came up with conclusion that media in the developing countries put much emphasis on domestic issues as compare to developed nations. Likewise, Young \& Dugas, [21] compare the climate change coverage of two different countries such as Canadian English and French language print media to explore the environmental values, media cultures and the narration of global warming in public sphere. They summarised that in the contemporary world climate change gradually has become the divisive issue, therefore media performing a key role in the promotion of contending claims and narratives in the public domain. Examined content of English and French newspapers from 2007-2008 explored the significant convergence as well as divergence among language divide. A significant finding explained that English press report the diverse compartmentalized coverage, whereas French newspapers portray a narrow range of coverage but with thematically sound approach that link climate change issues with dominions of politics, culture and economy. However, another comparative study, a comparison of local and regional newspapers in India regarding environmental issues concluded that media frame the environmental reality in scientific and political frames, and the reporting of environmental issues is more nationalist in nature than localize [18]. 
Previous study endorses the findings of [22] in which they examined the print and electronic media content in the US from 1988 to 2004 and summarised that news media contribute a major role in shaping climate change information but proliferation in news coverage dominate the political perspective than science in climate talks. However, Anderson, [16] emphasize on the role of news media with regard to readers understanding of the environmental issues and also its contribution in shaping their beliefs and perspective. On the other hand, in the reporting of environmental issues [23] conducted the research about reporting pattern of environmental news in online or digital age and outlined a range of journalistic practices. Environmental reporters canbe more digitally advance and vigilant in the digital age for the better construction of news content. On the other hand, unfortunately, still environmental items taken as filler in the absence of pivotal major news stories in the print media [24]. This is a known fact that many factors influence the news framing of environmental issues such as time, space, editorial policy, ownership, news cultures and advertising etc. in this vein comparative analysis of different countries can help to understand framing and reporting agendas of media outlets.
Though, a transnational comparative analysis of U.K and USA [25] explored that coverage in the media outlets reflects the system in which they prevailed. The framing of climate change in United States and British media imitate the norms of their own system, as coverage of US is event driven whereas UK reflects both cyclical, event driven liberal model of media and the more issue focused European model. Although, [1] found that media framing on climate change coverage dominated with political economic frame. Four major news magazines of USA over past 20 years were analysed a number of elements including primary frames, depth of coverage, section placement, sources of information and verbiage. This content analysis of 476 articles identified framing science as neutral towards a valid science frame.

\section{Balance Reporting}

George W. Bush stated on June 11, 2001 that, America has spent approximately 18 billion dollars on climate change research since 1991, more than any other country, such as Japan and other 15 EU countries together [26]. Through this time, prominent global climate scientists comprising of the United Nations-sponsored InterGovernmental Panel on Climate Change (IPCC) enhanced the understanding about global warming and formed three imperative and significant reports along 
with supportive documents. Consequently, IPCC develop the alarming argument of anthropogenic climate change and immediate solution to this matter. However, IPCC represented the managerial scientific discourse by holding up remarkable scientific consensus particularly on both issues global warming and anthropogenic influences [27]. On the conflicting side journalists mitigates against the accurate, meaningful as well as alarming reporting of global warming. Since, public is highly dependent on mass media about science issues [28]. Role of mass media in reporting of environmental issues such as global warming is imperative. Popular discourse about climate change is diverged from scientific discourse by using filter of balance reporting [29]. Many of researches have examined the potential ability of mass media in transmitting or communicating sufficiently or accurately scientific findings about greenhouse gases, global warming and climate change [30-33]. However, a variety of studies have keenly explored and identify the factors that lead towards the insufficient and inaccurate coverage [3436]. While, Ungar [35] supported the previous argument and divulged that "science is an encoded form of knowledge that requires translation in order to be understood". Several studies have focused on the effective communication failures of information from scientists to the media [37-39] and media to the masses $[30,34$, 37]. Mass media play a persuasive role in construction of environmental content [40]. Accordingly, coverage of elite press of global warming is not just the transmission of news but a kind of social relationship that built between people via news articles. Largely, the parameter of this social relationship defined by the journalistic norms and values, both influence what is considered as news and how it frames [27, 34]. However, much research has focused on the philosophical and cultural systems that influence the news coverage [41, 42], but this study explores the journalistic norm of balance reporting that affect the construction of news coverage. Bennet [43] contend that news content is influenced by three normative orders including, political norms (major task of mass media is to provide political information to the citizens in order to maintain the accountability of the elected officials), economic norms (reporting of journalists are affected by capitalist society where reporting is not less than profitable business), journalistic norms (fairness, accuracy, objectivity, balance). All three journalistic norms are interlinked and difficult to extricate from each other but in this study we focus on the journalistic norm of balance reporting. 
Relatedly, Gans [14] define, "Political balance is usually achieved by identifying the dominant, most widespread, or most vocal positions, then presenting both sides". While, balance coverage doesn't mean always accurate coverage. In fact, specifically to the coverage of global warming can actually leads towards the informational bias while balanced reporting. Therefore, Boykoff \& Boykoff, [4] have examined journalistic norm of balance reporting in American press and found that adherence towards the balance reporting actually leads to the biased coverage of climate change. In spite of IPCC highly regarded published reports regarding the anthropogenic human input in climate change and its immediate solution, still global warming skeptics viewpoint amplified under the umbrella of balance reporting. However, Ross Gelbspan [44] and Boykoff \& Boykoff [4] have asserted, the professional practical journalistic norm of balance reporting requires the equal attention or weight given to both sides of conflicting issues that are particularly social or political in nature, but the same principle could bring problems while reporting of science issues, "it seems to demand that journalists present competing points of views on a scientific question as though they had equal scientific weight, when actually they do not". On the other hand, we agreed upon the Bennett [43] conception of ideological bias that is inherently irresolvable. The utility of term bias is referred by Entman [11] as informational bias he explained it as "joint product of internalized professional values and of newsgathering routines". This consequently leads towards the distorted news, therefore Gans, [14] compare the term bias with distortion. He argues that "objective or absolute news content without distortion is impossible and the notion bias as distortion is still valid, but only as relational one". An unconditional conceptualization of bias traced in a relational perspective, align with conception of bias used to employ in this study. Boykoff \& Boykoff [4] well explained the word informational bias as "a historical product of the ever emergent social relations between mass media workers, scientists, politicians, and citizens".

A variety of framing studies solely focused on the coverage pattern of environmental issues in the media with some specific related issues. Little focus has been paid on the comparative analysis of developing and developed countries media systems to distinguish the journalistic norm of balance reporting while covering environmental issues. 
Therefore, how the news media frame environmental issues on the transnational level to compare their balance reporting patterns and framing priorities is an important issue to be researched because media disseminate the information about environment to the masses. The theoretical ground of this study found on the concept of framing by Entman, [12] and journalistic norm of balance reporting by $[4,7,10]$.

Following mentioned objectives and research questions has been addressed in this study:

\section{Objectives}

- To determine the frequently used frames in the reporting of Pakistani and British newspapers about environmental issues.

- To identify the environmental stance of Pakistani and British print media

\section{Research Questions}

- Which frames are most prominent in coverage of environmental issues across in the mainstream newspapers of Pakistan and United Kingdom (The Dawn, The Nation, The Guardian and The Telegraph)?

- Does reporting of environmental news is balance or biased in Pakistani and British print media?

\section{METHODOLOGY}

This study explores the reporting patterns of Pakistani and British prestigious press on Paris climate change agreement in the capacity of environmental issues by the use of quantitative method of content analysis. This approach explains the differences between the print media discourse in the UK and Pakistan, to identify the journalistic norm of balance reporting while covering the scientific discourse of Paris climate change agreement. This project proceeds the empirical steps to reveal the journalistic norm of balance reporting in develop and developing countries.

\section{Sampling}

In order to collect the scientific evidence, systematic reading of news stories occurred. Unit of analysis that have selected from four elite newspapers such as The Telegraph, The Guardian, The Dawn and The Nation. Each paragraph of a news story was considered as unit of analysis. The Telegraph and The Guardian are considered as elite press and representing the view point of British press. The Guardian is considered as a left-oriented newspaper in the British media system (National Dailies, 2019). Whereas, The Dawn and The Nation both are most popular elite newspapers of Pakistan. However, Pakistan was taken as developing countries nexus whereas UK taken as the part of developed nations nexus. Our sample comprises of prestigious press news 
stories from 2015-2016. This time period was taken for climate change coverage because an agreement known as Paris climate change occurred between this time period. Sample was compiled through the use of Lexis -Nexis advanced search engine data base with the use of key words "Paris climate change" and retrieved the required data. We have excluded opinion articles, editorials, letters to the editor, columns and book reviews. Other irrelevant subjects such as Fashion, Sports, Real Estate were omitted. With the use of these selection parameters, 298 total number of news stories appeared in all four newspapers, while classified number of news stories in The Dawn were 39 and in The Nation they were 24. However, in The Telegraph number of news stories were 37 and in The Guardian news stories were 198. Off these news stories, approximately $13.1 \%$ came from The Dawn, $8.1 \%$ from The Nation, $12.4 \%$ from The Telegraph and 66.4\% from The Guardian. Our sample consists of 105 news stories, which is $35 \%$ of the population. A simple random procedure of sampling was used byusing a computer program

www.psychicscience.org/random.aspx (accessed 2 January, 2019), [45]. Furthermore, $(\mathrm{n}=105)$ divided by two for equal distribution of news stories in developed and developing countries nexus, each of newspaper obtained 26 news stories.

This project reveals the journalistic norm of balance as well as dominant frames appeared in the reporting of environmental news stories from the prominent print media outlets of Pakistan and UK.

\section{Coding and measures}

This study approached two measures for the content analysis, firstly it identified prominent frames used in the reporting of 'Paris climate change agreement' secondly explored the journalistic norm of balance in the reporting of Pakistani and British print media regarding environmental issues. Frames typology is being used to analyse the news content of Pakistani and British newspapers get the idea of frames from the studies of [46, 47]. After conducting a pilot study, following mentioned frames were explored and modelled as relevant for the comparative analysis of Paris climate change agreement. Frames have been measured with their absence or presence in the news stories therefore present frame was considered as prominent in the news story. Frames were coded as absent (0) or present (1) in the news story. Hence, if a news story contained more than one frame then all present frames were taken as prominent frames. This approach identifies the presence or absence of below mentioned frames in the news stories of 
The Dawn, The Nation, The Guardian and The Telegraph.

- Informative frame

- Analytical frame

- Advisory frame

- Solution oriented frame

- Sensational frame

- Political frame

- Blame game frame

Balance of a news story was measured by identifying the dominant sources. Sources, designated as actors paraphrased or quoted in the news stories. Sources were classified as environmentalists versus environmental sceptics, if a news story contain equal number of sources from environmentalists and environmental sceptics then it wouldn't be the balance story. Consequently, if a news story dominating with the view point of environmental sources than environmental sceptics, it was taken as balanced story. Journalistic norm of balance reporting in science discourse of environment is different from other social or political issues covered with conventional idea of balance reporting by presenting the both sides with equal proportion. Therefore, more number of times a source covered in a news story coded as dominant with value (1). The dominance of sources in the news coverage was measured as balanced or bias reporting of environmental issues. If proportion of environmental sources are greater than environmental sceptic sources it was taken as balanced reporting, opposite to this claim it was considered as biased reporting.

\section{ANALYSIS}

We have analysed the data set through the statistics of descriptive analysis. This investigation reveals the reporting pattern of environmental issues in the coverage of Pakistani and UK elite press. Essentially, this study examined the existence of prominent frames in the reporting of Pakistani and British print media. Twentysix (26) news stories were analysed from The Nation as mainstream print media of Pakistan. Overall findings reveal the frame allocation in the news stories and found that an overwhelmed majority of responses shows ten(10) news stories focused on political frame, seven (7) news stories hold solution oriented frame, five (5) news stories contain informative frame, and a minimum frequency of value only four (4) news stories covered advisory frame. However, blame game, analytical and sensational frames were absent in the coverage of Pakistani mainstream newspaper The Nation. Political and solution oriented frames are most prominent in the environmental news coverage of Pakistan's leading newspaper The Nation. 
On the other hand, in the nexus of developing countries print media The Dawn also covered total number of twenty$\operatorname{six}(26)$ news stories in which seven (7) covered analytical frame, nine (9) consists of advisory frame, four (4) news stories focused on solution frame and five (5) contain political frame. While, representation of blame game, sensational, and informative frames were non-existent. Interestingly, advisory and analytical frames are most prominent in Paris climate change coverage of The Dawn. Generally, in Pakistani print media including (The Nation and The Dawn) collectively ignore the blame game, and sensational frames in their news coverage about Paris climate change agreement. However, The Telegraph leading newspaper of the developed country UK covered twenty-six (26) news stories, in which five(5) were focused on sensational frames, seven (7) covered political, eight (8) contain blame game and six (6) news stories covered informative frame. However, advisory, solution oriented, and analytical frames were absent in the environmental news coverage of The Telegraph. Moreover, British print media such as The Guardian covered total number of twenty-six (26) news stories in which seven (7) focused on blame game, five (5) emphasised on political frame, seven (7) news stories covered solution oriented frame, four (4) news stories based on advisory frame whereas only three (3) environmental news stories highlighted the analytical frame. Though, informative and sensational frames were not present in the news coverage of The Guardian. Surprisingly, Blame game and political frames were mutually dominant in the news coverage of British Newspapers The Telegraph and The Guardian regarding news coverage of Paris climate change agreement. Secondly, this study explored presence of dominant sources in the reporting of environmental issues across Pakistani and British print media. Environmentalists sources were dominant in each of newspaper including The Guardian with the number of twentythree (23) news stories, The Telegraph with twenty-one (21) news stories, twenty-six news stories (26) in The Dawn and nineteen (19) news stories in The Nation inclined towards the pro environmental sources. Though, environmental sceptic sources were covered in the concerned newspapers with diverse frequency values. Such as three (3) news stories in The Guardian, five (5) news storiesin The Telegraph, and seven (7) news stories in The Nation highlighted the environmental sceptic sources. However environmental sceptic sources were entirely non-existent in the news coverage of Pakistani elite 
newspaper The Dawn. Dominance of environmentalists sources in news stories describe the journalistic norm of balance reporting whereas, minimum presence of environmental sceptic sources considered as biased reporting in the coverage of environmental issues.

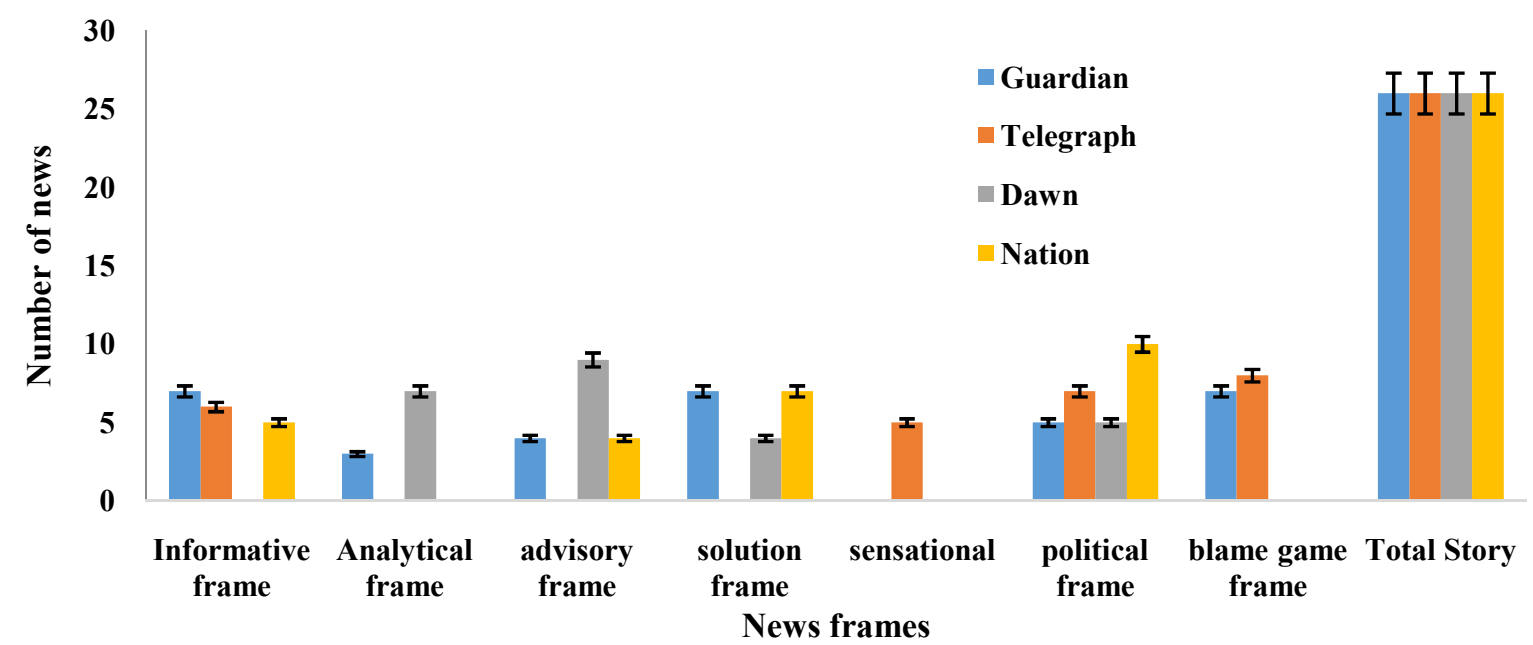

Figure 1: Most prominent frames in the coverage of environmental issues in Pakistani and British print media

Table 1: Dominance of news sources in the reporting of environmental issues across print media of Pakistan and UK

\begin{tabular}{|c|c|c|c|c|}
\hline Name of Publication & $\begin{array}{c}\text { Environmentalist sources } \\
\text { Dominance }\end{array}$ & $\begin{array}{c}\text { Environmental sceptics } \\
\text { Presence }\end{array}$ & Balanced & Biased \\
\hline The Guardian & $\mathbf{2 3}$ & $\mathbf{3}$ & $\sqrt{ }$ & $\mathbf{X}$ \\
\hline The Telegraph & $\mathbf{2 1}$ & $\mathbf{5}$ & $\sqrt{ }$ & $\mathbf{X}$ \\
\hline The Dawn & $\mathbf{2 6}$ & $\mathbf{0}$ & $\sqrt{ }$ & $\mathrm{X}$ \\
\hline The Nation & 19 & 7 & $\sqrt{ }$ \\
\hline
\end{tabular}

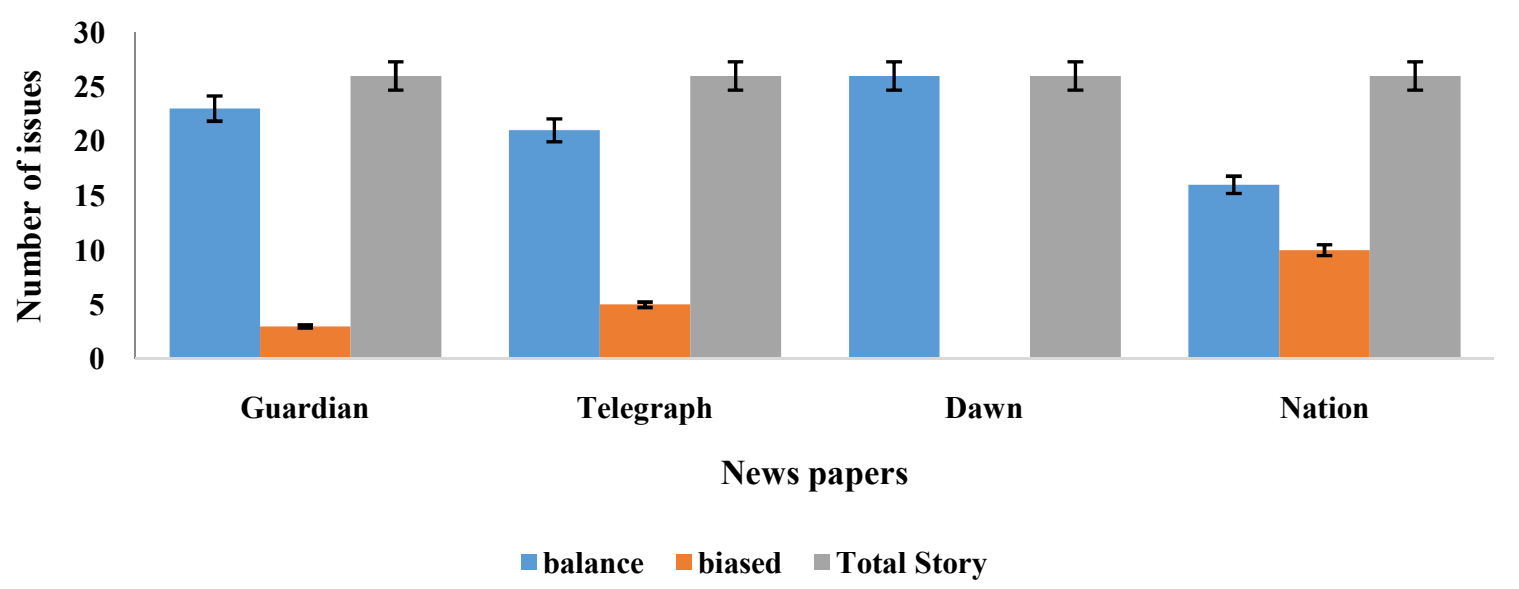

Figure 2: Balance or bias reporting of environmental news in Pakistani and British print media

\section{DISCUSSION AND CONCLUSION}

Overall, findings of this study explored the journalistic treatment of Pakistani and
British print media and found the prominent frames used in the Paris climate change agreement coverage and balance or 
biased approach relatedly. Commonly, sensational and blame game frames were completely non-existent in Pakistani print media. However, sensational frame was absent in the coverage of elite newspapers of England. Pakistani and British journalists of selected newspapers used proper and appropriate frames according to the organizational agenda of their concerned newspaper to shed light on the Paris climate change agreement as an environmental concern. As quantification of news story revealed the priorities of each media organization regarding environment. Accordingly, Pakistani print media specifically The Nation has not given much coverage to this issue in the selected time period. Paris climate change agreement was low on the priority list of one of Pakistan's elite newspaper's (The Nation) agenda. However, Pakistani elite newspaper (The Dawn) gives satisfactory amount of coverage with comparison to The Nation and The Telegraph. On the other hand, in British print media Telegraph has given lowest coverage to this issue as compare to The Guardian. One of the print media outlet of developed country, this much low coverage opens up a debate for Telegraph agenda about the environmental issues. As discussed above about the selection of different frames in Pakistani and British print media, it has concluded that Pakistani print media report the Paris climate change agreement with appropriate journalistic skills without any sensational drama, but British print media reporting to this issue contained versatile frames with diverse sources reflected in the news stories by putting the view point of two sides such as perspective of environmentalists and environmental sceptics. In the news stories of Pakistani selected news papers related to Paris climate change do not reflect the diversity in the perspectives of environmental stakeholders. As the set parameter for the journalistic norm of balanced reporting, we have opted [4] approach which they have used in their study about the coverage of global warming in US prestigious press to explore balance and bias reporting. Accordingly, balanced reporting to science issue represents more proportion of environmentalist sources than environmental sceptics [48, 49]. Findings of Pakistani and British print media revealed that in reporting of environmental issues of Pakistani and British print media environmentalist sources were dominant in both countries print media with slight difference while environmental sceptics get less coverage that leads towards the balanced reporting. British print media report the Paris climate change agreement with diversity of news sources but 
Pakistani print media don't reflect plurality of sources. However, this comparison between reporting of environmental issues in Pakistani and British elite press helpful in condensing some of complex journalistic practices featured in the news stories to adherence the journalistic norm of balanced reporting within the organizational agenda of each media outlet.

\section{REFERENCES}

[1] McCann. Framing study of media coverage on climate change from1989 to 2009. (2010), Master's thesis. San José State University, United States.

[2] Gamson, William, A. and Modigliani, Andre. "Media discourse and public opinion on nuclear power: A constructionist approach". American Journal of Sociology, 95, no. 1, (1989), pp. 1-37.

[3] Antilla, Liisa. "Climate of scepticism: US newspaper coverage of the science of climate change". Global environmental change, vol. 15, (2005), pp. 338-352.

[4] Boykoff, Maxwell. and Boykoff, Jules ,M. "Bias as balance: Global warming and the U.S Prestige Press". Global Environmental Change, vol. 15, no. 2, (2004), pp. 125-136.

[5] Smith, Joe. "Dangerous news: media decision making about climate change risk." Risk analysis: an official publication of the Society for Risk Analysis, vol. 25, no. 6, (2005), pp. 1471-82.

[6] Carvalho, Anabela. "Media (ted) Discourses and Climate Change. A focus on political subjectivity and (dis)engagement". WIREs Climate Change, vol. 1, no. 2, (2010), pp. 172-179.

[7] Boykoff, Maxwell T. "From convergence to contention: United States massmedia representations of anthropogenic climate change science". Transactions of theInstitute of British Geographers, vol. 32 no. 4, (2007b), pp. 477-489.

[8] Holstein, Lisa. and Stocking, Holly, S. Manufacturing doubt: Journalists' roles and the construction of ignorance in a scientific controversy. Conference Papers-International Communication Association, (2006). $1-34$

[9] Foust, Christina, R, et al. "Revealing and reframing a pocalyptic tragedy in global warming discourse". Environmental Communication, vol. 3 no. 2, (2009), pp. 151-167.

[10] Boykoff, Maxwell T. "Flogging a dead norm? Newspaper coverage ofanthropogenic climate change in the United States and United Kingdom 
from 2003to 2006". Area, vol. 39, no.

4, (2007a), pp. 470-481.

[11] Entman, Robert, M. Democracy without Citizens: Media and the Decay of American Politics. Oxford University Press, New York and Oxford, 1989.

[12] Entman, Robert, M. "Framing: Toward clarification of a fractured paradigm". Journal of Communication, vol. 44, no. 4, (1993), pp. 51-8.

[13] Hedding. Is it hotter out there or is it just the media: A comparative framing analysis of climate change in the New York Times and the Guardian. (2011). Master's thesis, University of Denver, United States.

[14] Gans, Herbert, J.Deciding What's News. Pantheon, New York, 1979.

[15] Graber, Doris, A. Processing the News: How People Tame the Information Tide. 2nd Edition, New York: Longman, 1988.

[16] Anderson, Alison. Media, Culture, and the Environment. New Brunswick, New Jersey, Rutgers University Press, 1997.

[17] Boykoff, Maxwell, T.“'Indian media representations of climate change in a threatened journalistic ecosystem". Climate Change, vol. 99, no. 1, (2010), pp. 17-25.
[18] Thirumalaiah, Nirmala and Aram, Arul. "Framing of environment in English and Tamil newspapers in India". Journal of media and communication studies, vol. 9, no. 1, (2016), pp. 1-9.

[19] Francis. Ethics in newspaper journalism in Kerala. (2014). Ph.D. thesis submitted to University of Kerala.

[20] Marukatat. A comparative content analysis of environmental news coverage in Time and The Weekly review. (1991). Master's thesis, Greenlee School of Journalism and Communication, lowa university USA.

[21] Young, Nathan. and Dugas, Eric."Comparing climate change coverage in Canadian English and French language print media: Environmental values, Media cultures and the narration of global warming". The Canadian journal of sociology, vol. 37, no. 1, (2012), pp. 25-54.

[22] Boykoff, Maxwell, T. and Boykoff, Jules, M."Climate change and journalistic norms: A case study of U.S. mass-media coverage". Geoforum, vol.38, (2007), pp. 11901204.

[23] Holliman, Richard. "Reporting environmental news: newspapers in 
the digital age". Frontiers in Ecology

and the Environment, vol. 5, no. 5, (2007), pp. 277-278.

[24] Adam, Barbara. "The media timescales of BSE news". Environmental risks and the media, edited by Stuart Allan and Adam, Barbara, London: Routledge, 2000, pp. 117.

[25] Boykoff, Maxwell, T. "Lost in translation? United States television news coverage of anthropogenic climate change, 1995-2004". Climate Change, vol. 86 no. 1/2, (2008), pp. 1-11.

[26] New York Times. In President's Words: 'A Leadership Role on the Issue of Climate Change'. New York Times, New York, 2001, p. A12.

[27] Adger, Neil, W, et al. "Advancing a political ecology of global environmental discourses". Development andChange, vol.32, no. 4, (2001), pp. 681-715.

[28] Nelkin, Dorothy. Selling Science: How the Press Covers Science and Technology. W.H. Freeman, New York, 1987.

[29] Weingart, Peter, et al. "Risks of communication: discourses on climate change in science, politics, and the mass media". Public Understanding of Science, vol. 9,
(2000), pp. 261-283.

[30] Bell, Allan. "Media (Mis) communication on the science of climate change". Public Understanding of Science, vol. 3, (1994a), pp. 259-275.

[31] Bell, Allan."Climate of opinion: public and media discourse on the global environment". Discourse and Society, vol. 5, no. 1, (1994b), pp. 3364.

[32] Dunwoody, Sharon, and Peters, Hans, Peter."Mass media coverage of technological and environmental risks". Public Understanding of Science, vol. 1, no. 2, (1992), pp. 99230.

[33] Nissani, Moti. "Media coverage of the greenhouse effect". Population and Environment: A Journal of Interdisciplinary Studies, vol. 21, no. 1, (1999), pp. 27-43.

[34] Wilson. "Mass media as sources of global warming knowledge". Mass Communications Review, vol. 22, no. (1\&2), (1995), pp. 75-89.

[35] Ungar, Sheldon. "Knowledge, ignorance and the popular culture: climate change versus the ozone hole". Public Understanding of Science, vol. 23, no. 3, (2000), pp. 297-312.

[36] Trumbo, Craig."Constructing climate 
change: claims and frames in US news coverage of an environmental issue". Public Understanding of Science, vol. 5, no. 1,(1996), pp. 269283.

[37] McComas, Katherine. and Shanahan, James."Telling stories about global climate change". Communication Research, vol. 26, no. 1, (1999), pp. $30-57$.

[38] Ungar, Sheldon. "The rise and (relative) decline of global warming as a social problem". The Sociological Quarterly, vol.33, no. 4, (1992), pp. 483-501.

[39] Zehr, Stephen.C."Public representations of scientific uncertainty about global climate change". Public Understanding of Science,vol. 9, (2000), pp. 85-103.

[40] Schoenfeld, A, Clay, et al. "Constructing a social problem: the press and the environment". Social Problems, vol. 27, no. 1,(1979), pp. 38-61.

[41] Schudson, Michael. Discovering the News: A Social History of American Newspapers. Basic Books, New York, 1978.

[42] Wilkins, Lee. "Between the facts and values: print media coverage of the greenhouse effect, 1987-1990". Public Understanding of Science, vol.
21, no. 1, (1993), pp. 71-84.

[43] Bennett, W, Lance."An introduction to journalism norms and representations of politics". Political Communication, vol. 13, no. 4, (1996), pp. 373-384.

[44] Gelbspan, Ross. The Heat is On The Climate Crisis, the Cover-Up, the Prescription. Perseus Press, Cambridge, Massachusetts, 1998.

[45] Bryman, Alan. Social Research Methods. $\quad 5^{\text {th }}$ edition, Oxford University Press, 2016.

[46] Brossard, Dominique, et al. "Are issue-cycles culturally constructed? A comparison of French and American coverage of global climate change". Mass Communication \& Society, vol.7, no. 3, (2004), pp. 359-377.

[47] Nisbet, Matthew, C. "Communicating climate change: Why frames matter in public engagement". Environment Magazine, vol. 51, no. 2, (2009), 1323.

[48] Creswell, John, W. Research Design. $4^{\text {th }}$ edition, Sage Publication, 2014.

[49] Spector, Malcolm. and Kitsuse, John. Constructing Social Problems. Cummings, Menlo Park, CA, 1977. 